\title{
Exploration of Molecular/Antigenic Mimicry between Trichuris ovis and its Ovine Host
}

\author{
Mamoni Das, Madhurendra Bachan, Ruma Jas*, Soumitra Pandit and Surajit Baidya
}

Department of Veterinary Parasitology, West Bengal University of Animal and Fishery Sciences, 37, Kshudiram Bose Sarani, Kolkata - 700 037, West Bengal, India

*Corresponding author

\begin{tabular}{l} 
Ke y w o r d s \\
$\begin{array}{l}\text { Antigens, Mimicry, } \\
\text { Trichuris ovis, } \\
\text { Sheep }\end{array}$ \\
\hline Article Info \\
$\begin{array}{l}\text { Accepted: } \\
\text { 06 August } 2018 \\
\text { Available Online: } \\
\text { 10 September } 2018\end{array}$ \\
\hline
\end{tabular}

Keywords

Antigens, Mimicry, Trichuris ovis, Sheep

Accepted:

06 August 2018 10 September 2018

\section{A B S T R A C T}

Trichuris ovis is one of the prevalent and non-pathogenic nematode of sheep. The whole anterior part of $T$. ovis remains embedded in the caecal mucosa of sheep with any marked inflammatory reaction. Helminth parasites evade host immune response by acquiring some host proteins or by mimicry of host antigens. The present study was conducted to explore any molecular mimicry between the $T$. ovis and sheep. Crude somatic antigen of anterior and posterior part of male and female and excretory-secretory antigen of $T$. ovis and the caecal mucosal antigen of sheep (CSAg-Ms) were prepared and antigenic characterization was done by SDS-PAGE and subsequently by western blot analysis with a view to detect any shared as well as cross-reactive antigens between T. ovis and CSAg-Ms. Five antigenic peptides $(57,51,31,21$ and $14 \mathrm{kDa})$ were common among the antigens of $T$. ovis and caecal mucosal antigen of sheep. Five immunogenic peptides $(75.6,55,47,37.8$ and 24 $\mathrm{kDa}$ ) of $T$. ovis showed cross-reactivity with the hyperimmune sera against CSAg-Ms raised in rabbits. Therefore the comparatively non-pathogenicity of $T$. ovis in sheep might be due to the presence of antigenic mimicry as well as cross-reactive antigens between $T$. ovis and its host.

\section{Introduction}

Trichuris ovis is one among the most prevalent nematode parasites infesting the caecum of small ruminants irrespective of age, gender, and breed of the host worldwide. Trichuris ovis occurs as a co-infection with other helminths and it rarely causes clinical disease in ruminants (Jas et al., 2016). Trichuris sp. is generally considered as nonpathogenic and in heavy infection they may cause haemorrhagic colitis and/or a diphtheritic inflammation of caecal mucosa
(Taylor et al., 2007). Trichuris sp. has a thickbroad posterior part and a long filamentous anterior part which contains the stichosome oesophagus. Stichosome oesophagus of Trichuris like that of Trichinella, is extremely narrow, embedded in a chain of large cylindrical cell, the stichocytes which collectively form the structure of stichosome (Urquhart et al., 1996). The stichocytes of Trichinella is rich in a variety of membrane bound granules which are highly immunogenic (Wakelin, 1984). The entire anterior part (stichosome oesophagus) of 
Trichuris ovis remains embedded in the mucosa without any marked inflammatory and/or immune response (Soulsby, 1982) though the mucous membrane is the major site for immune response against gut pathogens. There are many lymphoid ( $\mathrm{T}$ and $\mathrm{B}$ lymphocytes) and non-lymphoid effector cells in the normal mucosa and their number increase during parasitic infection (Wakelin, 1984).

Studies of the immune response against helminths are of great interest in understanding interactions between the host immune system and parasites. Worms are able to persist in the host and are mainly responsible for chronic infection despite a strong immune response developed by the parasitized host. Helminths have developed several means of escaping these immune responses. Recently, Maizels et al., (2004) called them "masters of immunomodulation". Several proteins produced by helminths were involved in the regulation of cytokine production (Harn et al., 2009, Hewitson et al., 2009). Host immune response to helminths is generally hampered by two main factors namely the complexity of antigenic profiles and the presence of cross- reactive determinants on antigens (Gamble et al., 1990; Cuquerella et al., 1994) of parasites or the molecular mimicry between the host and parasites (Damian, 1987).

While some species of Trichuris such as $T$. vulpis (dog, fox), T. suis (pig) and T. trichiura (man) are pathogenic (Soulsby, 1982) the nonpathogenicity of $T$. ovis might be due to unresponsiveness of host immune system to the antigens of $T$. ovis. Therefore the antigenic characterization and cross-reactivity among the antigens of $T$. ovis and host mucosal antigen were carried out with a view to detect the presence, if any, molecular mimicry between the $T$. ovis and caecal mucosal protein of sheep.

\section{Materials and Methods}

\section{Experimental animals}

Healthy New Zealand white strain rabbits $(n=14)$ were used for raising hyperimmune serum (HIS) against crude somatic antigens (CSAg) and excretory-secretory antigen (ESAg) of T. ovis and caecal mucosal protein of sheep. Rabbits were maintained under conventional conditions with the provision of feed and water ad libitum in the Institutional Animal House for laboratory animals. The animal experimentation was designed following the standard guidelines of the Committee for the Purpose of Control and Supervision of Experiments on Animals (CPCSEA) and was approved by the Institutional Animal Ethical Committee, West Bengal University of Animal and Fishery Sciences, India.

\section{Collection of $T$. ovis and preparation of their crude somatic antigens}

For collection of T. ovis the caecum and colon of slaughtered sheep were collected from local abattoir. The male and female worms from the excised organs were separately collected with the help of a forceps in $0.15 \mathrm{M}$ phosphate buffer saline (PBS, $\mathrm{pH}$ 7.2). The worms were then washed 4-5 times in 0.15M PBS (pH 7.2) Then the anterior and posterior portion of each worm both male and female were separated by cutting with the help of a fine scissors. Finally, the anterior and posterior portion of male and female worms were homogenized separately in $10 \mathrm{ml}$ of chilled $0.15 \mathrm{M}$ PBS (pH-7.2) containing Phenyl methyl sulfonyl fluoride (PMSF)@25mM and Ethelene diamine tetra acetic acid (EDTA) @ $24 \mathrm{mM}$ in a homogenizer $\left(\mathrm{IKA}^{\mathrm{R}} \mathrm{T} 10\right.$ basic Homogenizer, Germany). Then the homogenized materials were centrifuged in a cold centrifuge (Hermle centrifuge, Germany) at $4^{\circ} \mathrm{C}$ at 10000 r.p.m. for 45 minutes. Then the supernatant was 
collected as a crude somatic antigen (Klesius et al., 1986). Crude somatic antigens (CSAg) of anterior portion of both male and female worms were concentrated with the help of Centriprep Centrifugal Filter Device (Millipore). At first $10 \mathrm{ml}$ distilled water (D. W.) was put inside the apparatus and centrifuged at 3000 r.c.f. for ten minutes. After centrifugation D.W. was discarded and the crude somatic antigens of anterior portion of both male and female $(10 \mathrm{ml})$ was poured separately in two devices and again centrifuged at 3000 r.c.f. for forty minutes.

After centrifugation the filtrate was collected as a concentrated antigen. Protein concentration of CS Ag was estimated by the method of Lowry et al., (1951). The protein content of CS Ag of anterior portion of male (CSAg-TMa) and female (CSAg-TFa) Trichuris were $2.58 \mathrm{mg} / \mathrm{ml}$ and $2.69 \mathrm{mg} / \mathrm{ml}$, respectively. The crude somatic antigen of posterior portion of male (CSAg-TMp) and female (CSAg-TFp) had the protein concentration of $3.66 \mathrm{mg} / \mathrm{ml}$ and $6.7 \mathrm{mg} / \mathrm{ml}$, respectively.

\section{Preparation of Caecal mucosal antigen} (CSAg-Ms) of sheep

For preparation of caecal mucosal antigen at first caecum of slaughtered sheep was excised and faecal material from the caecum was cleaned properly in running tap water. Then the mucosal surface was washed two times with normal saline solution (NSS) and then washed three times with PBS (pH-7.2). The mucosal surface was scrapped with the help of a scalpel from different areas of caecum and kept in a petri dish.

About 5gm of mucosal tissue was washed five times with PBS (pH-7.2) containing 1000 IU/ $\mathrm{ml}$ penicillin, 1mg/ $\mathrm{ml}$ streptomycin and fluconazole. After washing $5 \mathrm{gm}$ of caecal tissue in $15 \mathrm{ml}$ of $\mathrm{PBS}$ (pH-7.2) was homogenized in tissue homogenizer $\left(\mathrm{IKA}^{\mathrm{R}}\right.$ T10 basic Homogenizer, Germany) and the homogenized materials was centrifuged at 10000 r.p.m. for 45 minutes at $4^{\circ} \mathrm{C}$. Then the supernatant was collected as caecal mucosal antigen. The protein content was estimated by the method of Lowry et al., (1951) and the protein concentration was $5 \mathrm{mg} / \mathrm{ml}$ and the antigen was preserved at $-20^{\circ} \mathrm{C}$ for further use.

\section{Preparation of Excretory- Secretory Antigen (ESAg) of T. ovis (ESAg-T)}

The excretory-secretory antigen of Trichuris ovis (ESAg-T) was prepared according to the method described by Prasad et al., (2008). The worms were collected from the caecum and colon of slaughtered sheep by the process stated as above and washed in the PBS for three times. Then the worms were washed three times in PBS (pH-7.2) containing 1000 $\mathrm{IU} / \mathrm{ml}$ penicillin and $1 \mathrm{mg} / \mathrm{ml}$ streptomycin and Fluconazole. Then the adult worms were put in RPMI 1640 supplemented with $2 \%$ glucose and incubated at $37^{\circ} \mathrm{C}$ for overnight in an atmosphere of $\mathrm{CO}_{2}$. After overnight incubation worms were removed from the medium.

Then the medium was centrifuged at 10000 $\mathrm{rpm}$ for $30 \mathrm{~min}$ at $4^{0} \mathrm{C}$. The supernatant was collected and concentrated with the help of Centriprep Centrifugal Filter Device (Millipore) as stated above. After centrifugation the filtrate was collected as excretory-secretory antigen (ESAg-T).

Then the concentrated antigen was filtered through $0.2 \mu \mathrm{m}$ filter membrane (Corning Sterile Syringe Filter, Germany). Phenyl methyl sulfonyl fluoride (PMSF) @ 25mM was added to the filtrate and stored at $-20^{\circ} \mathrm{C}$ for further use. Protein concentration of ESAg-T was estimated by the method of Lowry et al., (1951) and the protein concentration was $1.75 \mathrm{mg} / \mathrm{ml}$. 
The raising of HIS against the prepared antigens

Hyper-immune sera against the parasitic antigens (CSAg-TMa, CSAg-TFa, CSAgTMp and CSAg-TFp) and caecal mucosal protein of sheep were raised in New Zealand White strain rabbits (Hudson and Hay, 1989). The antigen $(0.5 \mathrm{mg}$ antigenic protein $)$ thoroughly emulsified with equal volume Freunds' complete adjuvant was injected intramuscularly and followed by four booster doses $(1.0,1.5,2.0$, and $2.5 \mathrm{mg})$ in equal volume of Freunds' incomplete adjuvant at weekly intervals. Blood from the hyperimmunized rabbits was collected 7 days following the last booster and then the separated serum was preserved at $-20^{\circ} \mathrm{C}$ till further use.

\section{Determination of peptide profiles of the antigens}

Protein profile of crude somatic antigen of $T$. ovis and caecal mucosal protein of sheep were determined by Sodium dodecyl polyacrylamide gel electrophoresis (SDSPAGE) in $10 \%$ gel as per the method of Laemmli (1970). Broad range molecular weight marker (10.0 to $250 \mathrm{kDa}$, Thermo Scientific, Lithuania) was used. After completion of the run, the separating gel containing different antigenic proteins were stained by Coomassie brilliant blue. The molecular weight (MW) of the unknown polypeptides of the test protein mixtures was determined by the Gel Documentation System, (BioRad, Japan).

\section{Antigenic characterization}

Antigenic characterization of the prepared antigens was done by western blotting technique using HIS raised in rabbits against the antigens under the present study. After separating the antigenic polypeptides by SDS-
PAGE, the gel lane having the marker was stained by Coomassie brilliant blue. The electrophoretic transfer of parasitic antigens resolved by SDS-PAGE was done by blotting onto a nitrocellulose membrane (BioRad, Mini-Size Nitrocellulose TransBlot Turbo) and immunoreactions development was carried out as per the standard method (Towbin et al., 1979). For the western blot analysis the dilution of HIS and the goat antirabbit IgG-horse radish peroxidase (HRPO) conjugates (GeNei, Bangalore) were 1: 50 and 1: 500, respectively. The molecular weight (MW) of the antigenic polypeptides was determined by the Gel Documentation System, (BioRad, Japan).

\section{Results and Discussion}

\section{Polypeptide profiles of the antigens}

The polypeptide profile of the six antigens under study was analyzed by SDS-PAGE and their polypeptide profiles are presented in Table 1. The CSAg-TMa revealed 7 polypeptides with the molecular weight (MW) ranging from $115-14.0 \mathrm{kDa}$ of which 57,51 , 39.5 and $31 \mathrm{kDa}$ polypeptides were found as dominant (Fig. 1). Ten polypeptides with the molecular weight (MW) ranging from $115-$ $12.6 \mathrm{kDa}$ were detected in CSAg-TFa by SDSPAGE (Table 1) and the dominant polypeptides were of $63,59,55,31 \mathrm{kDa}$ (Fig. $1)$.

SDS-PAGE analysis of CSAg-TMp revealed 11 polypeptides MW ranging from 224.2 $10.2 \mathrm{kDa}$ (Table 1) and four polypeptides having the MW of 47, 29.3, 15 and $12 \mathrm{kDa}$ were recorded as dominant (Fig. 2). Eleven polypeptides (MW ranging from $224.2-10.2$ $\mathrm{kDa}$ ) were detected by SDS-PAGE in CSAgTFp (Table 1). Five polypeptides (107, 75.6, 60.3, 47 and $35.2 \mathrm{kDa}$ ) in CSAg-TFp were detected as dominant polypeptides in SDSPAGE analysis (Fig. 2). Out of eleven 
polypeptides of ESAg-T (MW ranging from $250-10.4 \mathrm{kDa})$ four polypeptides $(250,31$, 24 and $17.2 \mathrm{kDa}$ ) were identified as the dominant polypeptides (Table 1) by SDSPAGE analysis (Fig. 3).

The Caecal mucosal protein of sheep revealed 9 polypeptides (MW ranging from 116.2 $14.3 \mathrm{kDa}$ ) in SDS-PAGE analysis (Table 1), out of which five polypeptides (65.2, 51, 41.2, 31 and $14 \mathrm{kDa}$ ) were recognized as dominant polypeptides (Fig. 1).

Antigenic characterization of $T$. ovis and host caecal mucosal protein

Western blot analysis using homologous antisera detected 6 immuno-reactive polypeptides (MW ranging from 57-14 $\mathrm{kDa}$ ) in CSAg-TMa (Table 2) of which 3 polypeptides with the MW of 51, 39.5 and 14 $\mathrm{kDa}$ were detected as the major immunoreactive polypeptides (Fig. 4). Out of 10 polypeptides of CSAg-TFa, 5 polypeptides (MW ranging from $63-16.7 \mathrm{kDa}$ ) were found immunogenic by western blot analysis using homologous antisera (Table 2) and the immunodominant polypeptides were of 55, 39.5 and $16.7 \mathrm{kDa}$ (Fig. 4).

Out of 11 polypeptides of CSAg-TMp four polypeptides were detected as immunogenic in western blot analysis against the homologous antiserum raised in rabbit (Table 2). The polypeptides in CSAg-TMp having the MW of $75.6,47$, and $15 \mathrm{kDa}$ were found as immunodominant (Fig. 5). Seven out of 11 polypeptides in CSAg-TFp were detected as immuno-reactive using homologous HIS (Table 2). The polypeptides having the MW of $159.1,107,60.3$ and $47 \mathrm{kDa}$ were found as immuno-dominant in CSAg-TFp (Fig. 5).

Out of 10 polypeptides of ESAg-T five polypeptides (MW ranging from 250 - 24 $\mathrm{kDa}$ ) were detected as immunogenic against the homologous HIS (Table 2). The polypeptides in ESAg-T having the MW of 51 and $31 \mathrm{kDa}$ were found as dominant immunepeptides (Fig. 6). Four polypeptides (MW; $65.2,51,31$ and $14 \mathrm{kDa}$ ) out of 9 polypeptides in CSAg-Ms reacted with homologous HIS in western blot analysis (Fig. 7). The immunodominant polypeptides were of $65.2,51$ and $31 \mathrm{kDa}$ (Table 2).

\section{Cross-reactivity between the antigens of $T$. ovis and host caecal mucosal antigen}

The results of cross-reactivity between the antigens (CSAg-TMa, CSAg-TFa, CSAgTMp, CSAg-TFp, ESAg-T) of T. ovis and host caecal mucosal protein as determined by western blot analysis using HIS against caecal mucosal protein of sheep under study were presented in Table 3. In case of CSAg-TMa, two dominant immunogenic polypeptides (MW; 51 and $21 \mathrm{kDa}$ ) cross-reacted with the HIS against CSAg-Ms (Fig. 7). Two immunogenic polypeptides (MW; 55 and 21 $\mathrm{kDa}$ ) of CSAg-TFa cross-reacted with the HIS against CSAg-Ms (Fig. 7) and both the polypeptides were recognized as immunedominant by the heterologous antisera.

Two immunogenic polypeptides (47 and 21 $\mathrm{kDa}$ ) of CSAg-TMp cross-reacted with the HIS against CSAg-Ms (Fig. 7) and only one polypeptide $(47 \mathrm{kDa})$ was the dominant crossreacting polypeptide and in case of CSAgTMp. Three immunogenic polypeptides (MW; 75.6, 47 and $21 \mathrm{kDa}$ ) of CSAg-TFp revealed cross-reactivity with the HIS against CSAgMs (Fig. 7) and out of these two polypeptides (MW; 75.6 and $47 \mathrm{kDa}$ ) were recognized as immune-dominant polypeptides.

Four immunogenic polypeptides (MW- 37.8, 31,24 and $21 \mathrm{kDa}$ ) of ESAg-T out of five showed cross-reactivity with the HIS against CSAg-Ms (Fig. 8) and the cross-reacting dominant polypeptides were of 31 and $21 \mathrm{kDa}$. 
Fig.1 Comparative polypeptide profile of ovine caecal mucosal protein (L-1), CSAg-TMa (L2) and CSAg-TFa (L3)

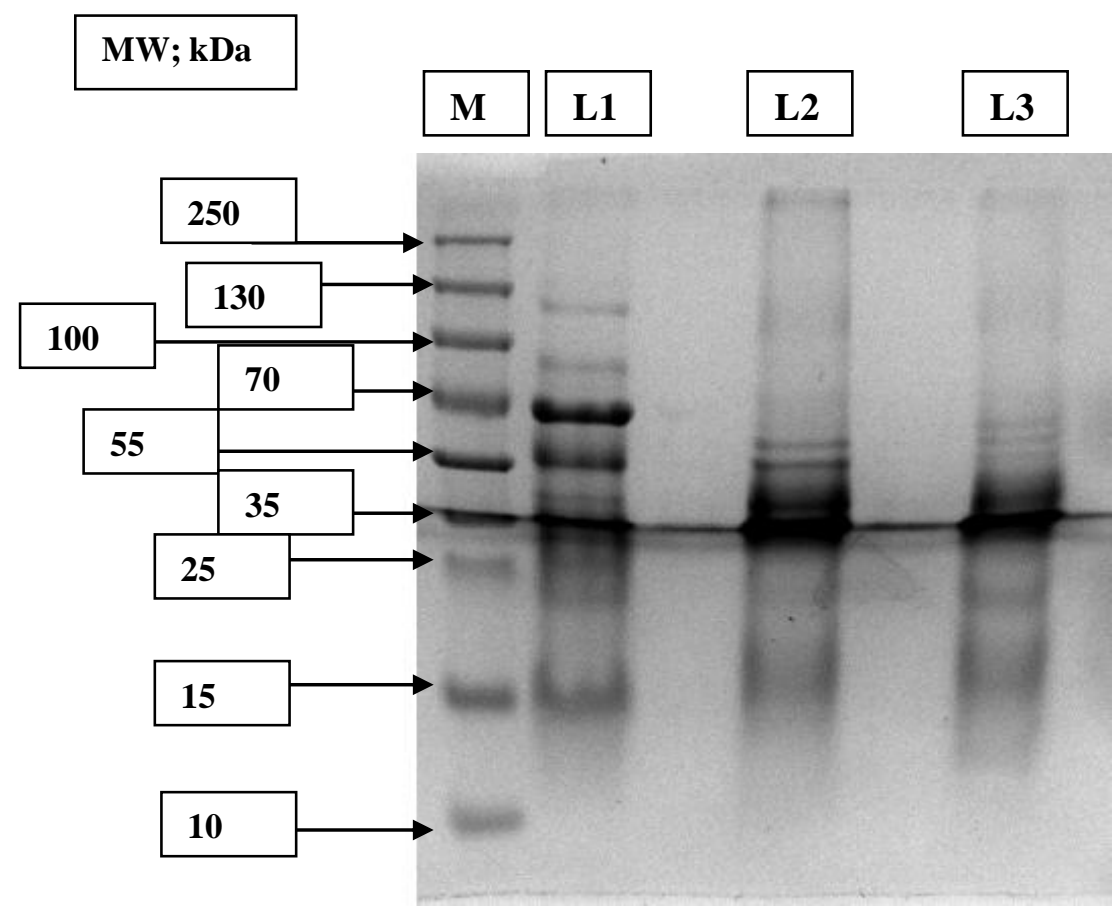

Fig.2 Comparative polypeptide profile of ovine caecal mucosal protein (L-1), CSAg-TMp (L2) and CSAg-TFp (L3)

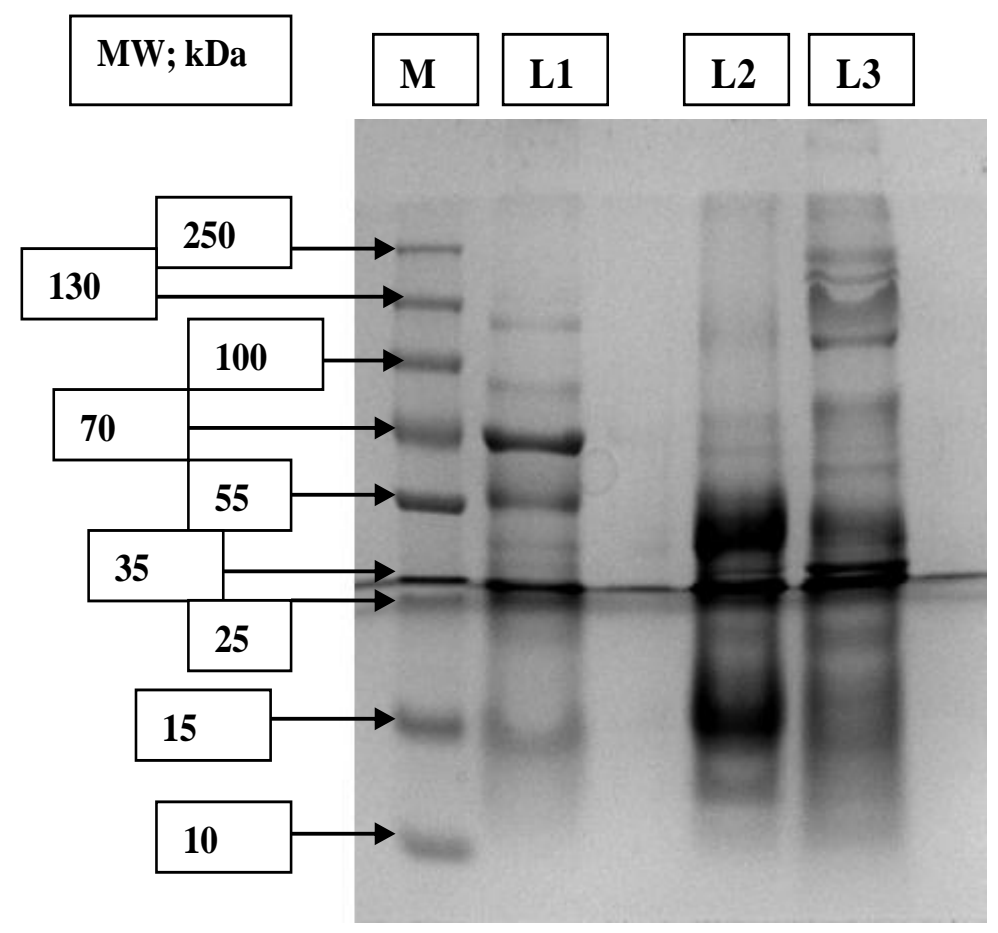


Fig.3 Comparative polypeptide profile of ovine caecal mucosal protein (L-1), and ESAg-T (L-3)

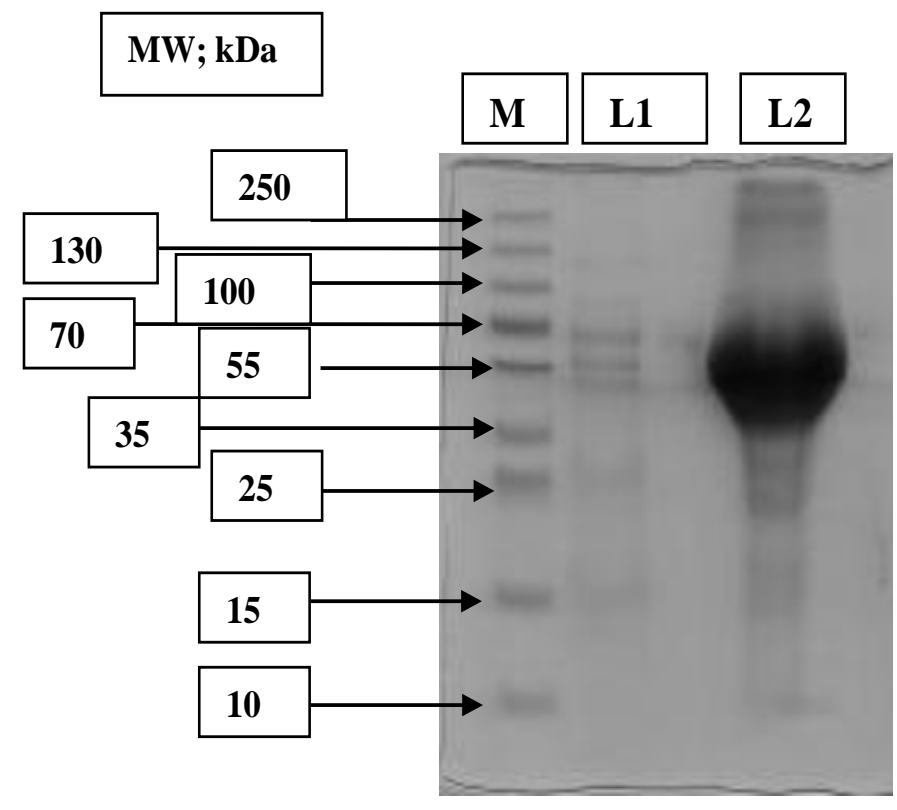

Fig.4 Western blotting Pattern of CSAg-TMa (L-1) and CSAg-TFa (L-2) against the homologous HIS

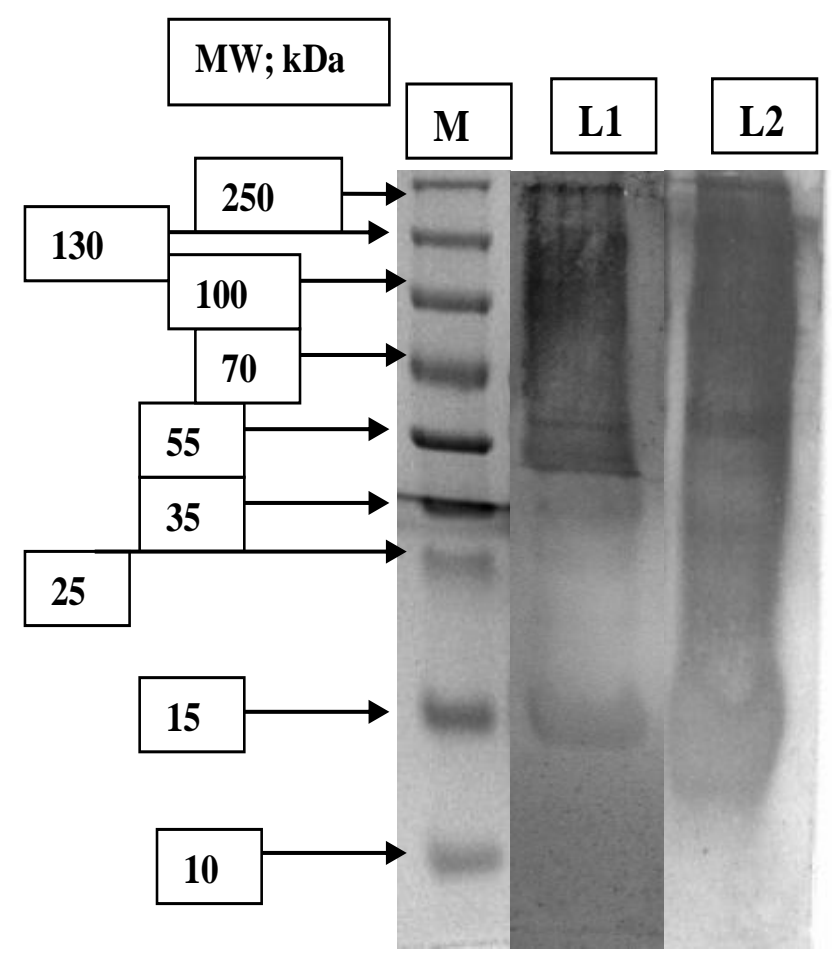


Fig.5 Western blotting Pattern of CSAg-TFp (L-1) and CSAg-TMp (L-2) against the homologous HIS

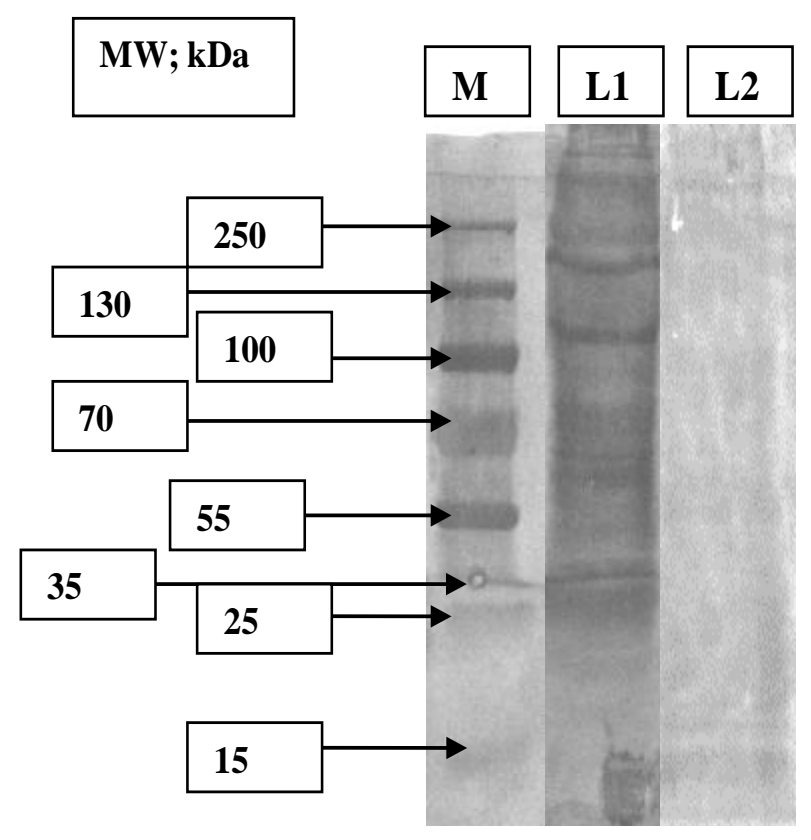

Fig.6 Western blotting Pattern of ESAg-T (L-1) against the homologous HIS

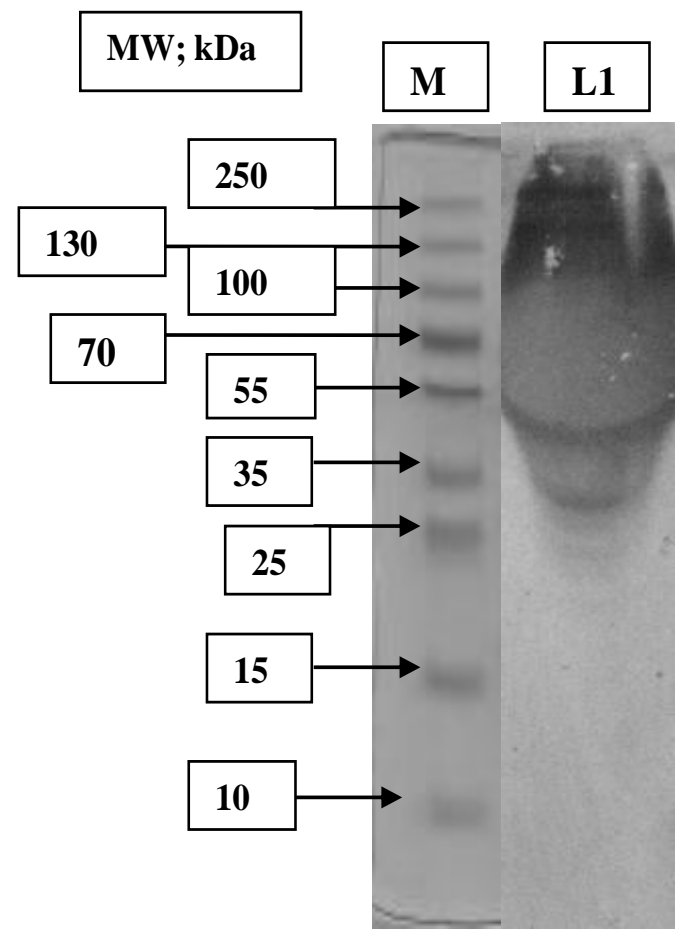


Fig.7 Western blotting pattern of CSAg-TFp (L-1), CSAg-TMp (L2), CSAg-TFa (L3), CSAgTMa (L4), and CSAg-Ms (L-5) using HIS raised against caecal mucosal protein

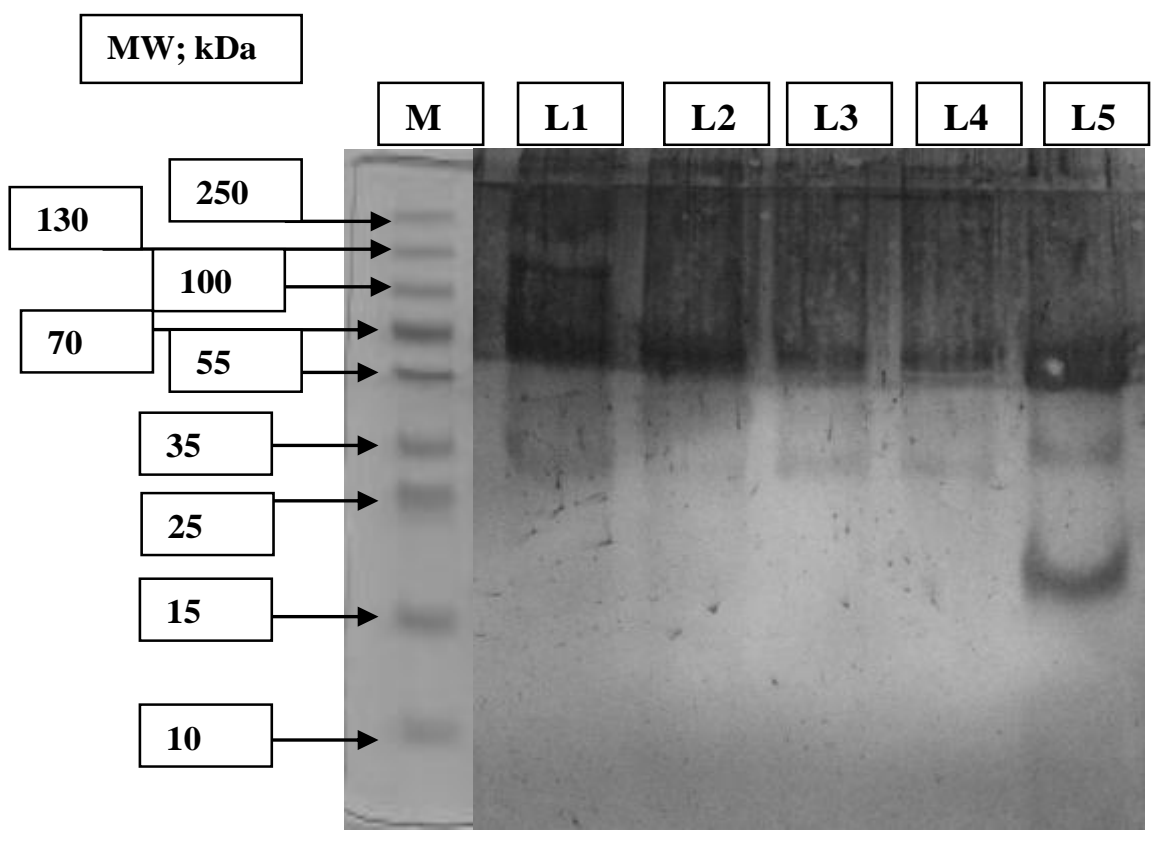

Fig.8 Western blotting pattern of ESAg-T (L-1) and CSAg-Ms (L-2) using HIS raised against caecal mucosal protein

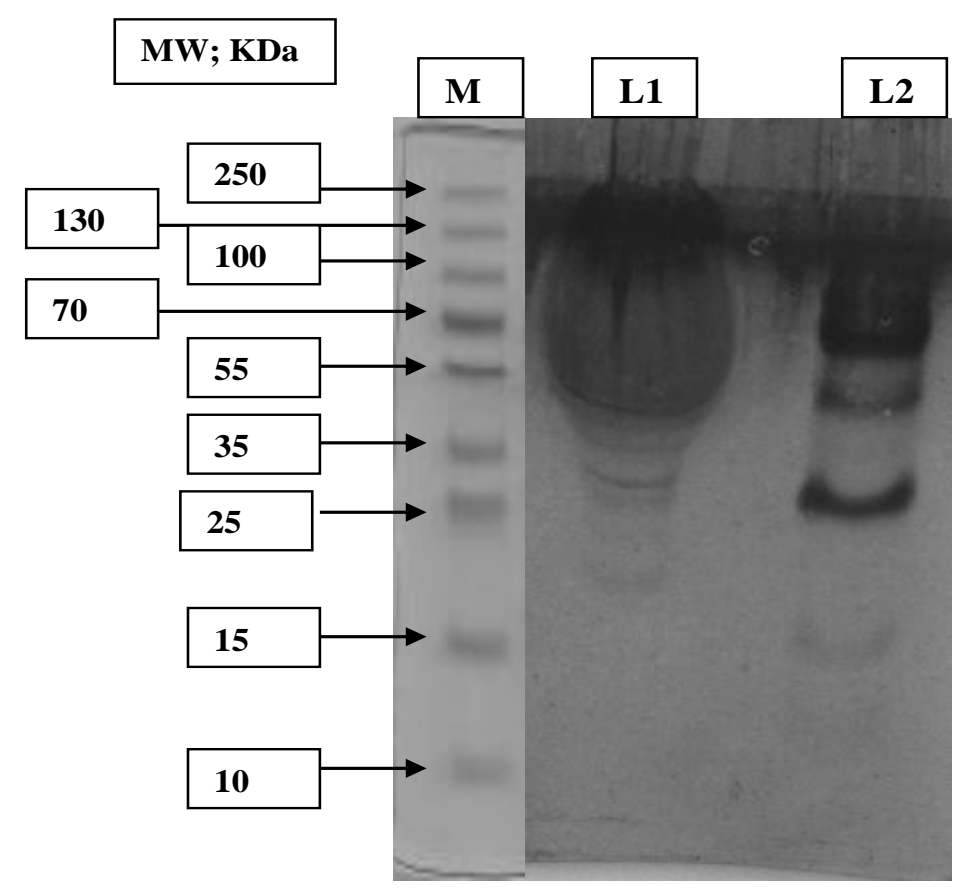


Int.J.Curr.Microbiol.App.Sci (2018) 7(9): 569-582

Table.1 Polypeptide profile of the various antigens as resolved by SDS-PAGE analysis

\begin{tabular}{|c|c|c|c|c|c|}
\hline $\begin{array}{l}\text { Sl. } \\
\text { No. }\end{array}$ & Antigens & $\begin{array}{c}\text { Range of } \\
\text { M.W. (kDa) }\end{array}$ & $\begin{array}{l}\text { No. of } \\
\text { peptides }\end{array}$ & M. W. (kDa) of the peptides & $\begin{array}{c}\text { Dominant } \\
\text { peptides }\end{array}$ \\
\hline 1 & $\begin{array}{l}\text { CSAg- } \\
\text { TMa }\end{array}$ & 14.0-115 & 7 & $115,57,51,39.5,31,21$ and 14 & $\begin{array}{c}57,51,39.5 \text { and } \\
31\end{array}$ \\
\hline 2 & CSAg-TFa & $12.6-115$ & 10 & $\begin{array}{c}115,63,59,57,55,39.5,31,21 \\
16.7 \text { and } 12.6\end{array}$ & $\begin{array}{c}63,59,55 \text { and } \\
31\end{array}$ \\
\hline 3 & $\begin{array}{l}\text { CSAg- } \\
\text { TMp }\end{array}$ & $10.2-224.2$ & 11 & $\begin{array}{c}224.2,159.1,107,75.6,65.2,47 \\
29.3,21,15,12 \text { and } 10.2\end{array}$ & $\begin{array}{c}47,29.3,15 \text { and } \\
12\end{array}$ \\
\hline 4 & CSAg-TFp & $10.2-224.2$ & 11 & $\begin{array}{c}224.2,159.1,107,75.6,60.3,47 \\
35.2,21,17.2,14 \text { and } 10.2\end{array}$ & $\begin{array}{c}107,75.6,60.3, \\
47 \text { and } 35.2\end{array}$ \\
\hline 5 & ESAg-T & $10.4-250$ & 11 & $\begin{array}{l}250,173.5,57,51,37.8,31,24 \\
21,17.2,15 \text { and } 10.4\end{array}$ & $\begin{array}{c}250,31,24 \text { and } \\
17.2\end{array}$ \\
\hline 6 & CSAg-Ms & 14-116.2 & 9 & $\begin{array}{c}116.2,85.2,65.2,57,51,41.2 \\
31,21 \text { and } 14\end{array}$ & $\begin{array}{l}65.2,51,41.2, \\
31 \text { and } 14\end{array}$ \\
\hline
\end{tabular}

Table.2 Immunogenic polypeptide profile of the various antigens as determined by western blot using homologous hyper immune sera

\begin{tabular}{|c|c|c|c|c|}
\hline Sl. No. & Antigens & HIS & Immunogenic Polypeptides & Dominant peptides \\
\hline 1 & $\begin{array}{c}\text { CSAg- } \\
\text { TMa }\end{array}$ & $\begin{array}{l}\text { HIS against } \\
\text { CSAg-TMa }\end{array}$ & $57,51,39.5,31,21$ and 14 & $51,39.5$ and 14 \\
\hline 2 & CSAg-TFa & $\begin{array}{l}\text { HIS against } \\
\text { CSAg-TFa }\end{array}$ & $63,55,39.5,31$ and 16.7 & $55,39.5$ and 16.7 \\
\hline 3 & $\begin{array}{l}\text { CSAg- } \\
\text { TMp }\end{array}$ & $\begin{array}{l}\text { HIS against } \\
\text { CSAg-TMp }\end{array}$ & $75.6,47,21$ and 15 & $75.6,47$ and 15 \\
\hline 4 & CSAg-TFp & $\begin{array}{l}\text { HIS against } \\
\text { CSAg-TFp }\end{array}$ & $\begin{array}{c}224.2,159.1,107,75.6,60.3,47 \text { and } \\
21\end{array}$ & $\begin{array}{c}159.1,107,60.3 \text { and } \\
47\end{array}$ \\
\hline 5 & ESAg-T & $\begin{array}{c}\text { HIS against } \\
\text { ESAg-T }\end{array}$ & $250,51,37.8,31$ and 24 & 51 and 31 \\
\hline 6 & CSAg-Ms & $\begin{array}{l}\text { HIS against } \\
\text { CSAg-Ms }\end{array}$ & $65.2,51,31$ and 14 & $65.2,51$ and 31 \\
\hline
\end{tabular}

Table.3 Cross-reacting polypeptide profile of the various antigens as determined by western blot using hyper immune sera against caecal mucosal protein of sheep

\begin{tabular}{|l|c|c|c|}
\hline S. No. & Antigens & $\begin{array}{c}\text { Cross-reacting Immunogenic } \\
\text { Polypeptides }\end{array}$ & Dominant peptides \\
\hline 1 & CSAg-TMa & 51 and 21 & 51 and 21 \\
\hline 2 & CSAg-TFa & 55 and 21 & 55 and 21 \\
\hline 3 & CSAg-TMp & 47 and 21 & 47 \\
\hline 4 & CSAg-TFp & $75.6,47$ and 21 & 75.6 and 47 \\
\hline 5 & ESAg-T & $37.8,31,24$ and 21 & 31 and 21 \\
\hline
\end{tabular}


Antigenic similarity or shared antigens between $T$. ovis and caecal mucosal antigen

Three polypeptides (57, 31 and $21 \mathrm{kDa})$ were common among the CSAg-TMa, CSAg-TFa, ESAg-T and CSAg-Ms (Table 1). One polypeptide of $31 \mathrm{kDa}$ was found immunereactive against the HIS raised against all the four antigens. Besides the above three, one polypeptide having the MW of $51 \mathrm{kDa}$ was shared among the CSAg-TMa, ESAg-T and CSAg-Ms and $14 \mathrm{kDa}$ polypeptide was common between CSAg-TMa and CSAg-Ms and both the polypeptides $(51 \mathrm{kDa}$ and 14 $\mathrm{kDa}$ ) were immunogenic. One polypeptide of $21 \mathrm{kDa}$ was shared among all the six antigens under study and this polypeptide showed immuno-reactivity with the HIS against CSAg-TMa, CSAg-TMp and CSAg-TFp (Table 2). Therefore a total of five antigenic polypeptides $(57,51,31,21$ and $14 \mathrm{kDa})$ were shared between $T$. ovis and host caecal mucosal protein (Table 1).

Antigenic complexity is a major challenge for immunological approaches to diagnosis and control of parasitic infections, especially for the helminths, which are metazoan organisms. Different antigens of Trichuris ovis of sheep viz., anterior and posterior part of both male and female parasite and also their excretorysecretory products were characterized to have an idea about the complexity of different antigens of $T$. ovis.

Earlier report on characterization of polypeptide profile of Trichuris ovis is very rare. Eight polypeptides (107, 59, 51, 47, $39.5,31,21$ and $12 \mathrm{kDa})$ of crude somatic antigens of $T$. ovis recorded in the present study have been reported earlier by Jas et al., (2016). The crude somatic antigen of anterior part of male $T$. ovis showed six immunogenic polypeptides whereas the posterior part showed four immunopeptides against the homologous rabbit antisera. In female $T$. ovis the anterior part revealed five immunogenic polypeptides and seven immunopeptides were recorded in the posterior part. Excretorysecretory (ES) product of helminth parasites have also attracted the attention of researchers as they display immunogenic properties and their nature of antigens are less complex compared to somatic antigens (Arunkumar, 2012).

In the present study excretory-secretory antigen of Trichuris ovis showed 11 polypeptides (MW; 250-10.4 kDa) of which 5 peptides $(57,51,31,21$ and $15 \mathrm{kDa})$ were shared with the different somatic antigens of Trichuris and six peptides $(250,173.5,37.8$, 24, 17.2 and $10.4 \mathrm{kDa}$ ) were specific for excretory-secretory products of Trichuris ovis. Sharing of antigens between the somatic and ES antigen of helminths has been reported earlier by Jas (2008) who reported that 3 peptides of 78,73 and $50 \mathrm{kDa}$ were shared between the CSAg and ES antigen of Oesophagostomum.

The interaction of host immune system and parasites is an emerging topic of research among the immunologists and molecular biologists all over the world. The nature of many parasitic worms is to modulate the host immune response and thereby conciliating some diseases and aggravating others in their host (Kamal and Khalifa, 2006). Immunogenic properties of caecal mucosal protein (CSAg-Ms) of sheep have not been recorded earlier. In the present study out of 9 peptides in CSAg-Ms four peptides were identified as immunogenic against HIS raised in rabbits. Five polypeptides caecal mucosal antigen of sheep were shared with the different somatic and ES antigens of Trichuris. Presence of shared antigens or epitopes among the helminth parasites have been reported widely (Jasmer et al., 1993). In the present study several shared antigens/immunogens have been detected. 
Antigenic cross-reactivity or crossantigenicity among the helminth parasites is one of the major limitations for developing a reliable tool for immunodiagnosis or for immunoprophylaxis against parasitic diseases. Cross-reactivity among the antigens of helminth parasites have been reported from all over the world (Cuquerella et al., 1994; Jas et al., 2016). Cross-reactivity between the somatic antigen of Trichuris and sheep caecal mucosal antigen has been observed in the present research. Two antigenic peptides (37.8 and $24 \mathrm{kDa}$ ) of ESAg-T cross-reacted with the HIS against the host caecal mucosal protein. One immunogenic peptide of $55 \mathrm{kDa}$ in CSAg-TFa was recognized by the antibody against sheep caecal mucosal protein. Crossreacting antigens between the $T$. ovis and host caecal mucosal protein might be playing some role in the unresponsiveness of host immune system to the $T$. ovis antigens and hence no marked inflammatory reaction at the site of attachment.

The immunological relationships between the parasites and their vertebrate host are complex and imperfectly understood. In this direction the sharing of antigens between parasite and host i.e. the molecular mimicry helps in understanding a little about the hostparasite immunological relationship (Damian, 1964). In the present study molecular mimicry between Trichuris ovis and sheep has been explored by demonstration of shared antigens/ immunogens between Trichuris ovis (somatic and ES) antigens and caecal mucosal protein of sheep using electrophoresis and immunoblotting technique. Five immunogenic peptides $(57,51,31,21$ and 14 $\mathrm{kDa}$ ) were shared between the antigens of Trichuris ovis and caecal mucosal protein of sheep. Molecular mimicry between parasites and their host is rare except few studies in Schistosoma. Host immune evasion by the schistosomes might be due to molecular mimicry and the parasite shared some antigens with the host (Damian, 1964) as observed sharing of antigens between $T$. ovis and its ovine host in the present study. Whole of the anterior part of Trichuris remains embedded in the mucosa and sub-mucosa of sheep without any gross severe local immunological or inflammatory response at the site of attachment though the mucosa and sub-mucosa of intestine is rich in cells of immune system (Wakelin, 1984). The site of attachment at the caecal mucosa does not reveal any gross immuno-pathological lesions and this might be due to the presence of shared immunogenic peptides between Trichuris ovis and its host. As a result of this some potent immunogens of $T$. ovis might be recognized as self by the host immune system which would not evoke any immune reaction against the parasite. The present study indicates the presence of shared antigens or molecular mimicry between $T$. ovis and its ovine host.

Antigenic nature of Trichuris ovis is complex. Antigenic mimicry has been recorded between the $T$. ovis and sheep, in which $T$. ovis shares some host caecal proteins. Therefore comparatively non-pathogenicity of Trichuris ovis might be due to the sharing of immunogenic peptides and cross-reactivity with the host caecal mucosal protein.

\section{Acknowledgement}

The authors thankfully acknowledge Late Prof. J. D. Ghosh and the financial assistance of the Indian Council of Agricultural Research, New Delhi in conducting this study under the research project entitled "All India Network Programme on Gastrointestinal Parasitism."

\section{References}

Arunkumar, S., 2012. Antigenic characterization of excretory/secretory 
antigen of Oesophagostomum columbianum using western blotting. CIBTech. J. Biotech. 1 (2 \& 3), $28-31$. Cuquerella, M., M. T. G. Munoz, L. Carrera, C. D. L. Fuente and Alunda, J. M. 1994. Cross antigenicity among ovine Trichostrongyloidea. Preliminary report. Vet. Parasitol. 53, 243 - 251.

Damian, R. T., 1964. Molecular mimicry: Antigen sharing by parasite and host and its consequences. Am. Naturalist. 98, $129-149$.

Damian, R. T., 1987. Molecular mimicry revisited. Parasitol. Today. 3, $263-$ 266.

Gamble, H. R., J. P. Purcell and Fetterer, R. H. 1990. Biochemical characterization of cuticle polypeptides from the infective larvae of Haemonchus. Comp. Biochem. Physiol. 96B, 421 - 429.

Harn, D. A., J. McDonald, O. Atochina and Da'dara, A. A. 2009. Modulation of host immune responses by helminth glycans. Immunol. Rev. 230(1), $247-$ 257.

Hewitson, J. P., J. R. Grainger and Maizels, R. M. 2009. Helminth immunoregulation: the role of parasite secreted proteins in modulating host immunity. Mol. Biochem. Parasitol. 167 (1):1-11.

Hill, D. E., R. D. Romanowski and Urban, J. F. 1997. A Trichuris specific diagnostic antigen from culture fluids of Trichuris suis adult worms. Vet. Parasitol. 68 (12), $91-102$.

Hudson, L., and Hay, F. C., 1989. Practical Immunology, $3^{\text {rd }}$ Ed. Blackwell Scientific Publication, Oxford, London. pp. 507.

Jas R. Studies on characterization and cross antigenecity of three commonly occurring gastrointestinal nematodes of goat and early diagnosis of caprine oesophagostomosis by enzyme linked immunosorbent assay. 2008. Ph.D thesis. West Bengal University of Animal and Fishery sciences, Kolkata.

Jas, R., J. D. Ghosh and Das, K. 2016. Antigenic Cross-reactivity among Haemonchus contortus, Oesophagostomum columbianum and Trichuris ovis of Goat. Iranian J. Parasitol. 11(4), 542 - 548.

Jasmer, D. P., L. E. Perryman, G. A. Conder, S. Crow and McGuire, T., 1993. Protective immunity to Haemonchus contortus induced by immunoaffinity isolated antigens that share a phylogenetically conserved carbohydrate gut surface epitope. J. Immunol. 151: 5450 - 5460.

Kamal, S. M., and Khalifa, K. E. S., 2006. Immune modulation by helminthic infections: worms and viral infections. Parasit. Immunol. 28(10), 483-496.

Klesius, P. H., S. M. Washburn and Haynes, T. B. 1986. Serum antibody response to soluble extract of the third larval stage of Ostertagia ostertagi in cattle. Vet. Parasitol. 20: 307 - 314.

Laemmli, U. K., 1970. Cleavage of structural proteins during the assembly of the head of bacteriophage $\mathrm{T}_{4}$. Nature. 227, $680-$ 685.

Lowry, O. H., N. J. Rosebrough, A. B. Farr and Randall, R. J. 1951. Protein measurement with the Folin-phenol reagent. J. Biol. Chem. 193, 265.

Maizels, R. M., A. Balic, N. Gomez-Escobar, M. Nair, M. D. Taylor and Allen, J. E. 2004. Helminth parasites - masters of regulation. Immunol. Rev. 201, 89 116.

Prasad, A., A. Nasir and Singh, N. 2008. Detection of anti-Haemonchus contortus antibodies in sheep by dotELISA with immunoaffinity purified fraction of ES antigen during perpatency. Ind. J Exp. Biol. 46, 94 99. 
Soulsby, E. J. L., 1982. Helminths, Arthropods and Protozoa of Domesticated Animals, 7th Ed. The English Language Book Society and Ballière Tindall, London. Pp. 334-336.

Taylor, M. A., Coop, R. L., Wall, R. L., 2007. Veterinary Parasitology, $3^{\text {rd }}$ Ed. Blackwell Publishing. Pp 489.

Towbin, H., T. Stachelin and Gorden, G. 1979. Elecrophoretic transfer of proteins from polyacrilamide gels to nitrocellulose sheets: Procedure and some application. Proceedings of the National Academy of Sciences, USA. 4350-4354.

Urquhart, G. M., J. Armour, J. L. Duncan, A. M. Dunn and Jennings, F. W. 1996. Veterinary Parasitology, 2nd ed. Blackwell Science, United Kingdom. pp. 307.

Wakelin, D., 1984. Immunity to Parasites. How Animals control Parasitic Infections. Edward Arnold, London. Pp. 109.

\section{How to cite this article:}

Mamoni Das, Madhurendra Bachan, Ruma Jas, Soumitra Pandit and Surajit Baidya. 2018. Exploration of Molecular/Antigenic Mimicry between Trichuris ovis and Its Ovine Host. Int.J.Curr.Microbiol.App.Sci. 7(09): 569-582. doi: https://doi.org/10.20546/ijcmas.2018.709.068 